\title{
Antibiotics in the Medical and Surgical Treatment of Necrotizing Enterocolitis. What Regimen is the Best? - A Systematic Review
}

Ester Maria Gill ( $\nabla$ ester.m.gill@gmail.com )

Odense Universitetshospital Kirurgisk Afdeling A https://orcid.org/0000-0003-0028-8828

Kristine Jung

Odense Universitetshospital Kirurgisk Afdeling A

Niels Qvist

Odense Universitetshospital Kirurgisk Afdeling A

Mark Ellebæk

Odense Universitetshospital Kirurgisk Afdeling A

\section{Research article}

Keywords: NEC, antibiotics, surgery, death

Posted Date: April 6th, 2021

DOI: https://doi.org/10.21203/rs.3.rs-384464/v1

License: @ (i) This work is licensed under a Creative Commons Attribution 4.0 International License. Read Full License 


\section{Abstract}

Background: The aim of this review was to identify relevant randomized controlled trials (RCTs) and non-RCTs to evaluate the existing knowledge on antibiotic treatment effect for infants with Necrotizing Enterocolitis (NEC).

Objective: Identifying 1) the best antibiotic regimen to avoid progression or surgery in infants with NEC 2) the best antibiotic regimen for infants operated for stage III NEC.

Methods: Embase, MEDLINE and Cochrane were searched systematically for human studies using antibiotics for patients with NEC. Eligible studies had patients with NEC Bells stage II and III. Study selection, data extraction, and quality assessment were performed independently by two authors. RoB2 and ROBINS-I were used where appropriate.

Results: 5 studies were included, 2 RCT and 3 n-RCT. Four regimens were investigated. Three used a combination of ampicillin + gentamycin (or similar) with an addition of 1) clindamycin 2) metronidazole or 3) enteral gentamycin. One studied investigated cefotaxime + vancomycin. None of the included studies had a specific regimen for stage III infants undergoing surgery.

Conclusions: A GRADE evaluation was not possible because of large heterogeneity. For now, there is not sufficient evidence to make a general recommendation on which antibiotic regimen is the most effective for infants with NEC stage II and III.

\section{Backgound}

1-3 of every 1000 newborns are affected by Necrotizing Enterocolitis (NEC)[1]. 90\% of cases are seen in very low and extremely low birthweight (BW) infants, with a gestational age $(\mathrm{GA})<32$ week[2]. Among the infants with the lowest BW and GA the incidence may be as high as $22 \%[2,3]$. The medical treatment consists of antibiotics and cessation of enteral feeding the rationale for this recommendation is immaturity of the gastrointestinal tract and the innate immune system. In severe cases (Bell's stage III[4]) surgery is required and the indication for postoperative antibiotic treatment is to prevent surgical site infections and re-NEC.

The antibiotic treatment of NEC empirically covers anaerobic and Gram-negative bacteria. The most common regimen will be intravenous ampicillin and gentamycin combined with metronidazole for a period of 10-14 days[5, 6]. In 2012 a Cochrane review[7] of randomized and quasi randomized studies was conducted and sufficient evidence for a general recommendation on an empiric NEC regimen could not be made. Several studies have investigated the effects of prophylactic antibiotics to prevent NEC in infants of risk. There is no evidence regarding its effectiveness $[8,9]$ and because of the associated patient and society risks, antibiotic administration for preventive causes should be evidence based and prescribed with caution[6]. Broad spectrum antibiotics covering both aerobic and anaerobic bacteria are recommended [10], because no single organism has proven to consistently cause the disease[11]. In an Australian study[6] NEC-patients with positive cultures from blood/feces/operative specimen or vascular access devices were examined to see if the first line treatment of Ampicillin, Gentamicin and Metronidazole was adequate to cover the bacteria identified in the cultures. Only 4 out of the 12 included cases were covered.

Several reviews have tried to recapitulate the most common treatment methods, but no standardized comparison exist $[5,7,12]$. Because of the relatively small and widespread patient population, it is difficult to conduct clinical randomized studies (RCT) with enough participants to achieve robust results which may explain the conflicting results and recommendations.

The lack of consensus on what antibiotic combination, administration and doses provides the best outcome for NEC-patients was the motive for this review. Because of the difficulties in creating RCTs within this field, this study also included non-randomized studies to investigate the knowledge derived from these types of studies.

The primary objective of the present study was to clarify which antibiotic regimen is the most effective for children with NEC to avoid progression of disease as assessed by operation or death.

The secondary objective was to identify the effect of antibiotic regimens in children with advanced disease, who have undergone surgery as assessed by the need for reoperation or death.

\section{Methods}

This systematic review was performed in accordance with the PRISMA guidelines[13]. 


\subsection{Study registration}

The study was registered in the PROSPERO register (CRD42020162193) January 15 ${ }^{\text {th }}, 2020$.

\subsection{Eligibility criteria}

Studies with documented NEC according to Bell's classification stage II or III, treatment with at least one type of antibiotic and with reported progression of the disease defined as surgery and/or death as an outcome were included. Exclusion criteria were 1) inability to obtain the full text and insufficient data on primary outcomes, 2) studies with overlapping data, 3) case reports 4) non-original articles such as reviews 5) articles not available in English or Scandinavian (Danish, Norwegian or Swedish).

\subsection{Information sources and search strategy}

The following databases were searched: Embase, Medline (both through Ovid) and Cochrane. Clinicaltrials.gov and Prospero were searched for any relevant ongoing trials or reviews. Opengrey.eu was searched to locate relevant grey literature within the area.

Relevant search terms were identified in Embase and Medline. The following search was conducted in Embase and adjusted to fit Medline and Cochrane format:

(prematurity[Emtree] or extremely low birthweight[Emtree] or very low birth weight[Emtree] or low birthweight [Emtree] or newborn[Emtree] or infant [Emtree] or Infant* or extremely premature infant*or premature infant* or premature neonate or pre-mature infant or pre-term bab* or pre-term child* or pre-term infant* or pre-term neonate or pre-term newborn or premature or premature bab* or premature child* or premature neonate* or premature newborn* or prematuritas or preterm bab* or preterm child* or preterm infant* or preterm neonate* or preterm newborn* or human neonate* or human newborn* or human infant* or Neonate* or Newborn child* or Newborn bab* or Neonatal Prematurity or Prematurity or Extremely Premature Infant* or Extremely Preterm Infant* or Extremely Premature Infant* or extremely low birthweight infant or extremely low birthweight infant or ELBW or very low birthweight infant or very low birth weight infant or VLBW or low birthweight infant or low birth weight infant or LBW) AND (necrotizing enterocolitis [Emtree] or necrotising enterocolitis or necrotizing enterocolis) AND (antiinfective agent [Emtree] or antibiotic agent [Emtree] or antibiotic prophylaxis [Emtree] or amoxycillin or amoxicillin or ampicillin or azithromycin or augmentin or benzylpenicillin or b-lactam or beta-lactam or beta-lactams or clarithromycin or cefuroxime or cotrimoxazole or co-trimoxazole or cefotaxime or ceftriaxone or ceftriaxone or cefditoren or chloramphenicol or cefpodoxime or cephradine or cephalexin or cefetamet or cefaclor or cephalosporin* or erythromycin or gentamicin or gentamycin or levofloxacin or minocycline or metronidazole or moxifloxacin or penicllin* or quinolone* or roxithromycin or sulphamethoxazole or sulfamethoxazole or trimethoprim or Antibiotic* or folate antagonists or combined antibiotic* or antibiotic or antibiotic prophylaxis or anti bacterial agent* or anti infective agent* or antibacterial agent* or antibacterial drug $^{\star}$ or antibacterial spectrum or antiinfective* or antimicrobial* or antiseptic* or microbiological agent* or Anti-Bacterial agent* or Antibacterial Agent* or Anti-Bacterial Compound* or Anti Bacterial Compound* or Bacteriocidal Agent* or Bacteriocide* or AntiMycobacterial Agent* or Anti Mycobacterial Agent* or Antimycobacterial Agent*).

The search was finalized by excluding conference abstracts from the search. A third search was performed by manually checking the references listed in the included studies. All relevant studies were included in the original search.

\subsection{Study selection}

Covidence ${ }^{14}$ was used for the screening process. The initial screening was carried out by the authors EMG and KJ. Included studies were screening based on title and abstract. If conflicts occurred, reasons for exclusion were discussed until agreement. Full text screening was carried out by the same two authors. In case of conflict, the article was discussed until a mutual agreement.

\subsection{Data collection and data items}

Data collection was conducted with a standardized piloted form within Covidence[14] and on an external platform allowing for extraction in duplicate by both authors. All extracted data was reviewed by both authors to ensure consistency in agreement. When information was missing from the included articles the author was contacted if possible.

The list of study items to be extracted was made according to the Cochrane handbook chapter 5[15] and modified according to relevance for this review. Extracted items included: Author name, title, publication year, study method, number of included infants, type 
of antibiotics used, doses, frequency and administration type, number of infants treated conservatively and undergoing surgery, number of deaths in each group and additional medicine administered as part of the treatment.

\subsection{Risk of bias in individual studies (methodological quality appraisal)}

RCTs were analyzed for bias using the Risk of Bias tool RoB2[16]. RoB2 evaluates the risk of bias in a study based on 5 domains of bias: 1) the randomization process 2) deviations from the intended intervention 3) missing outcome data 4) measurement of the outcome 5) selection of the reported result. Each domain is graded low, high, some concerns or no information according to a set of signaling questions, and later summed in an algorithm to determine bias level. The n-RCTs included were analyzed using ROBINS-I[17]. ROBINS-I evaluate how well the n-RCT study handles bias spread across 7 domains compared to a well performed RCT. The 7 domains are: 1) Confounding 2) selection of participants 3 ) classification of interventions 4) deviations from intended interventions 5) missing data 6) measurement of outcomes 7) selection of reported results. A n-RCT might therefore have been without major risks of bias compared to other studies of the same type, but compared to a RCT have issues, e.g. arising from randomization. All analyses were conducted at study level.

\subsection{Risk of bias across studies}

To estimate the risk of bias across studies, the intended assessment was to use GRADE. However, as the included studies were reviewed, it proved impossible to use this method because of too large heterogeneity.

\section{Results}

\subsection{Study selection}

The search resulted in 115 references from Cochrane library, 2063 from Embase, 534 from MEDline and 13 from Cochrane trials. A total of 2715 references. No relevant ongoing studies were identified on clinicaltrials.gov nor was any material found on Opengrey.eu at the time of search (updated February $24^{\text {th }}, 2021$ ).

EndNote initially removed 379 duplicates. The remaining 2336 references were uploaded to Covidence for screening (Fig 1.). A total of 5 studies were included, 2 RCT and 3 cohort studies. The two RCTs have previously been included in a Cochrane review.[7]

On September $12^{\text {th }}, 2020$, the search was repeated. A total of 264 new references was added (Endnote initially removed 2 duplicates). The new references were screened by the author EMG, none fulfilled the inclusion criteria.

\subsubsection{Reasons for exclusion of studies}

Several articles were excluded due to the wrong population; this was because the articles either included infants with non-confirmed NEC (studies investigating prophylaxis) or investigated the development of NEC based on antibiotic usage by the mother. The studies excluded for wrong study design was mainly reviews or animal studies. Wrong comparator/intervention was used when studies switched between mixed treatment as this could be a possible confounder for the primary outcome[4]

\subsection{Included studies}

Table 1. Study Characteristics of included studies 


\begin{tabular}{|c|c|c|c|c|c|c|c|}
\hline Study & Year & Methods & Participants & Interventions & $\begin{array}{l}\text { Primary } \\
\text { outcomes }\end{array}$ & & $\begin{array}{l}\text { Secondary } \\
\text { outcomes } \\
\text { Reported by the } \\
\text { study }\end{array}$ \\
\hline RCTs & & & & & Death & $\begin{array}{l}\text { Surgery } \\
\text { (including } \\
\text { surgery for } \\
\text { stricture, } \\
\text { perforation, } \\
\text { and re-NEC) }\end{array}$ & \\
\hline Hansen[18] & 1980 & $\begin{array}{l}\text { RCT } \\
\text { Randomization } \\
\text { from number } \\
\text { table } \\
\text { Blinded } \\
\text { intervention }\end{array}$ & $\begin{array}{l}20 \text { infants } \\
\text { Overall } \\
\text { mean GA: } \\
35.2 \text { weeks } \\
\text { Overall } \\
\text { mean BW: } \\
2200 \mathrm{~g}\end{array}$ & $\begin{array}{l}\text { IV ampicillin } \\
150 \mathrm{mg} / \mathrm{kg} / \mathrm{day} \\
\text { ev. } 6 \text { hours }+ \text { IM } \\
\text { gentamicin } 7.5 \\
\mathrm{mg} / \mathrm{kg} / \mathrm{day} \text { ev. } \\
8 \text { hours } \\
\text { Intervention } \\
\text { Group: + oral } \\
\text { gentamicin } \\
\text { through } \\
\text { nasogastric } \\
\text { tube } 15 \\
\mathrm{mg} / \mathrm{kg} / \text { day ev. } \\
4 \text { hours }\end{array}$ & $\begin{array}{l}\text { Intervention: } \\
1 / 10 \\
\text { Control:2/10 }\end{array}$ & $\begin{array}{l}\text { Intervention: } \\
1 / 10 \\
\text { Control: } \\
4 / 10\end{array}$ & $\begin{array}{l}\text { Intestinal } \\
\text { perforation } \\
\text { Intestinal stricture } \\
\text { Peritonitis }\end{array}$ \\
\hline Faix[19] & 1988 & $\begin{array}{l}\text { RCT } \\
\text { Randomization } \\
\text { by sealed } \\
\text { envelopes } \\
\text { Unclear } \\
\text { information } \\
\text { about blinding }\end{array}$ & $\begin{array}{l}42 \text { infants } \\
\text { Overall } \\
\text { mean GA: } \\
29,4 \text { weeks } \\
\text { Overall } \\
\text { mean BW } \\
1300 \mathrm{~g}\end{array}$ & $\begin{array}{l}\text { IV ampicillin (< } \\
7 \text { days old } 100 \\
\mathrm{mg} / \mathrm{kg} / \mathrm{day} \text { ev. } \\
12 \text { hours. }>7 \\
\text { days old } 150 \\
\mathrm{mg} / \mathrm{kg} / \mathrm{day}) \mathrm{ev} \text {. } \\
8 \text { hours }+\mathrm{IV} \\
\text { gentamicin } \\
\text { (<34 weeks GA } \\
5.0 \mathrm{mg} / \mathrm{kg} \\
\text { initialy then } 2.5 \\
\mathrm{mg} / \mathrm{kg} / \mathrm{day},>34 \\
\text { weeks } \mathrm{GA} \text { and } \\
<7 \text { days of age } \\
5.0 \mathrm{mg} / \mathrm{kg} / \mathrm{day} \\
\text { ev. } 12 \mathrm{hours}, \\
>34 \text { weeks of } \\
\mathrm{GA} \text { and }>7 \\
\text { days of age } 7.5 \\
\mathrm{mg} / \mathrm{kg} / \mathrm{d} \text { ev. } 8 \\
\text { hours. } \\
\text { Intervention } \\
\text { group: + IV } \\
\text { clindamycin } 20 \\
\mathrm{mg} / \mathrm{kg} / \mathrm{day} \text { ev. } \\
8 \text { hours }\end{array}$ & $\begin{array}{l}\text { Intervention: } \\
4 / 20 \\
\text { Control: } \\
4 / 22\end{array}$ & $\begin{array}{l}\text { Intervention: } \\
6 / 20 \\
\text { Control: } \\
4 / 22\end{array}$ & $\begin{array}{l}\text { Bowel necrosis } \\
\text { Strictures } \\
\text { Time to successful } \\
\text { reinstitution of } \\
\text { enteral feeds } \\
\text { Time to resolution } \\
\text { of intestinal } \\
\text { pneumatosis }\end{array}$ \\
\hline nRCTs & & & & & & & \\
\hline Vermeylen[20] & 1985 & $\begin{array}{l}\text { Prospective } \\
\text { cohort } \\
\text { All children } \\
\text { admitted } \\
\text { during 1978-84 } \\
\text { included }\end{array}$ & $\begin{array}{l}77 \text { infants, } \\
\text { (Group 1 } \\
\text { included } \\
1978-80= \\
22 \text { infants, } \\
\text { Group 2 } \\
\text { included } \\
\text { after } 1980 \\
=55 \\
\text { patients). } \\
\text { Overall } \\
\text { mean GA: } \\
34 \text { weeks } \\
\text { Overall } \\
\text { mean BW: }\end{array}$ & $\begin{array}{l}\text { IV ampicillin + } \\
\text { gentamycin + } \\
\text { enteral } \\
\text { gentamycin 10- } \\
15 \mathrm{mg} / \mathrm{kg} / \mathrm{day} \\
\text { ev. } 4 \text { hours } \\
\text { Intervention } \\
\text { group: IV } \\
\text { ampicillin + } \\
\text { aminoglycoside } \\
+ \text { IV } \\
\text { metronidazole } \\
\text { booster } 15 \\
\text { mg/kg followed } \\
\text { by } 7,5-10 \mathrm{mg} \\
\text { ev. } 12 \text { hours. } \\
\text { Page } 5 / 12\end{array}$ & $\begin{array}{l}\text { Intervention: } \\
8 / 53 \\
\text { Control:7/22 }\end{array}$ & $\begin{array}{l}\text { Intervention: } \\
\text { 17/24 } \\
\text { Control: } \\
4 / 22\end{array}$ & $\begin{array}{l}\text { Length of } \\
\text { hospitalization }\end{array}$ \\
\hline
\end{tabular}




\begin{tabular}{|c|c|c|c|c|c|c|c|}
\hline Scheifele[10] & 1987 & $\begin{array}{l}\text { Prospective } \\
\text { cohort } \\
\text { All children } \\
\text { admitted } \\
\text { during August } \\
\text { 1982- May } \\
1985 \text { included }\end{array}$ & $\begin{array}{l}90 \text { infants } \\
\text { (1982- } \\
83=46 \\
\text { infants } \\
\text { included, } \\
\text { from 1984- } \\
85=44 \\
\text { included } \\
\text { infants) } \\
\text { Overall } \\
\text { mean BW: } \\
1904 \mathrm{~g} \\
\text { GA? }\end{array}$ & $\begin{array}{l}\text { 1982-83: IV } \\
\text { ampicillin } 100 \\
\text { mg/kg/day + IV } \\
\text { gentamicin 5- } \\
7.5 \text { mg/kg/day. } \\
\text { If age < } 7 \text { d ev. } \\
12 \text { hours, other } \\
\text { ev. } 8 \text { hours. } \\
1984-85 \\
\text { Intervention } \\
\text { group: IV } \\
\text { cefotaxime } 150 \\
\text { mg/kg/day + IV } \\
\text { vancomycin } 30- \\
35 \text { mg/kg/day. } \\
\text { If age <7d ev. } \\
12 \text { hours, other } \\
\text { ev. } 8 \text { hours. }\end{array}$ & $\begin{array}{l}\text { Intervention: } \\
0 / 44 \\
\text { Control: } \\
5 / 46\end{array}$ & $\begin{array}{l}\text { Intervention: } \\
13 / 44 \\
\text { Control: } \\
15 / 46\end{array}$ & $\begin{array}{l}\text { Peritonitis } \\
\text { Intestinal } \\
\text { perforation } \\
\text { Thrombocytopenia } \\
\text { Recurrent NEC } \\
\text { Intestinal strictures }\end{array}$ \\
\hline Luo[21] & 2015 & $\begin{array}{l}\text { Retrospective } \\
\text { cohort } \\
\text { Infants treated } \\
\text { from Jan } 2008 \\
\text { to March } 2015 . \\
\text { Controls were } \\
\text { chosen using } \\
\text { PS-matching }\end{array}$ & $\begin{array}{l}146 \text { infants } \\
\text { (73 } \\
\text { intervention } \\
\text { group) } \\
\text { Overall } \\
\text { mean GA } \\
38.86 \\
\text { Overall } \\
\text { mean BW } \\
2909 \mathrm{~g}\end{array}$ & $\begin{array}{l}\text { All infants } \\
\text { recieved a } \\
\text { combination of } \\
\text { broad-spectrum } \\
\text { antibiotics such } \\
\text { as: } \\
\text { semisynthetic } \\
\text { penicillins, } \\
\text { cephalosporin, } \\
\text { carbapenems, } \\
\text { vanco-mycin. } \\
\text { Intervention: IV } \\
\text { metronidazole } \\
15 \text { mg/kg/day }\end{array}$ & $\begin{array}{l}\text { Intervention: } \\
9 / 73 \\
\text { Control:7/73 }\end{array}$ & $\begin{array}{l}\text { Intervention: } \\
11 / 73 \\
\text { Control: } \\
6 / 73\end{array}$ & $\begin{array}{l}\text { sepsis } \\
\text { blood transfusion } \\
\text { Need for } \\
\text { nasogastric } \\
\text { suction }\end{array}$ \\
\hline
\end{tabular}

Table 1.. All included infants had radiological evidence of NEC. Abbreviations: IM= intramuscular. IV=intravenous. PS=propensity score.

All included studies (table 1) treated infants with NEC Bells stage II-III[4]. None of the studies investigated a specific postoperative antibiotic regimen for stage III infants. All infants continued the study specific treatment they had received before surgery.

\subsection{Results of bias in individual studies}

Both included RCTs (figure 2[22]) gave rise to some concern for bias in domain 5 (bias due to selection of reported result) because no pre-specified plan for study analysis was available and outcome measures were not presented in advance according to the criteria stated in Rob2[16]. For the study by Hansen et al.[18] domain 4 gave rise to some concern for bias because the outcome assessors role in the study was unclear.

As for the nRCTs one study[21] was performed in a methodological manner comparable to a RCT. Two studies had one or more areas that gave reason to concern for bias.

In the study by Vermeylen et al.[20] information about statistical analysis of differences between the two groups compared were missing (domain 1). Scheifele et al.[10] provided well analyzed information about possible confounders, but according to standards specified by the ROBINS-I tool it cannot be compared to a well performed RCT.

\subsection{Risk of bias across studies}

For the N-RCTs all studies had a low risk of bias regarding bias due to deviation from intended intervention (D4), missing data (D5), measurement of outcomes (D6) and selection of reported results (D7). Only one study could receive a low risk of bias equal to a well performed RCT.

With the limited number of studies and difference in study setup it was decided not to calculate the weight of each individual study as this would be misleading. Only one study was judged to be of overall low risk of bias[21], and it was decided there was no substance 
for a generalization (figure 3). No synthesis of studies was conducted due to the heterogeneity of the studies. The GA varied from 29 to 38 weeks showing a great difference in the developmental stage for the infants at the onset of NEC (Table 1).

\subsection{Primary outcomes: death and surgery for stage II infants}

In the study by Luo et al.[21] 17 infants deteriorated to stage III in a population of 143 infants. 11 of these were being treated with metronidazole and 6 without. Clinically there was a lower mortality rate in the group receiving metronidazole, but the difference was not statistically significant.

In the study by Vermeylen et al.[20] the mortality rate was reduced from $3 / 18(16 \%)$ in the control group to $3 / 23(13 \%)$ in the intervention group receiving metronidazole (no statistical calculations).

\subsection{Primary outcomes: death and surgery for stage III infants}

Two studies specified the number of deaths within stage III infants. Vermeylen et al.[20] reported 5/30 deaths in the intervention group (supplemented with metronidazole), compared to $4 / 4$ deaths in the control group (a significant mortality reduction from 100-16\%). In the study by Luo et al.[21] 1/11 infants receiving metronidazole died, and 2/6 died without, this too was non-significant.

\subsection{Effects of intervention}

In some of the studies it was not possible to obtain results for stage II and III infants, respectively. In the study by Faix et al.[19] there was no significant difference in the rate of bowel necrosis (perforation and gangrene) between the two groups (ampicillin+ gentamicin vs. ampicillin+gentamin + clindamycin). Hansen et al.[18] showed no significant differences regarding perforation, strictures, or death in the population of 20 infants (ampicillin+ gentamicin vs ampicillin+ gentamicin + oral gentamicin).

In the study by Scheifele et al.[10] children with a birthweight $>2200 \mathrm{~g}$ had better outcomes regardless of treatment. No infants in this group died but had a similar risk of surgery as children with a birthweight below $2200 \mathrm{~g}$. For the group of infants with a BW $<2200 \mathrm{~g}$, the group receiving standard treatment (ampicillin and gentamicin) had a significantly higher risk $(p=0.004)$ for surgery, peritonitis, strictures, but not for re-NEC (4/34 infants $p=0.07)$. No infants $<2200 \mathrm{~g}$ treated with cefotaxime/vancomycin died compared to $5 / 38$ in the control group $(p=0.048)$.

\section{Discussion}

We found 5 studies reporting on 4 different treatment regimes. Although some few statistically significant differences emerged, and two studies[20,21] implied a trend towards a positive effect from metronidazole, we were not able to demonstrate constant findings to recommend neither the type of antibiotics, administration format or duration.

The 4 different regimes investigated by the included studies could be separated into the following groups 1) anaerobic antibiotics, 2) aminoglycosides 3 ) the combination of a cephalosporin and vancomycin. Four of the included studies used the combination of Ampicillin and gentamicin in some way[10, 18-20]. Although all studies reported on death and surgery as an outcome it was not all studies that separated the outcomes between stage II and III making a separate recommendation on antibiotics for stage II and III difficult. Especially knowledge on the treatment for stage III infants after surgery was scarce. Notable findings were: The cefotaxime/vancomycin regimen[10] showed significantly lower risk for surgery, and the regimen of oral clindamycin[19] had significantly higher cases of strictures.

A study[26] from 2020 evaluated the use of antibiotics for NEC at their institution. The assessment revealed large variation in antibiotics combination and duration. 14 different types were combined, with ampicillin + gentamicin + metronidazole being used the most. The study investigated medical NEC (defined as stage II) and surgical NEC (stage III), and overall found no superior combination or duration of treatment. The study did imply that in general longer treatment duration for both medical and surgical NEC had no benefit.

During the search, a study from 2019 by Harutynyan et al.[23] was discovered. The study was not included because the number of deaths in stage I infants could not be separated. The study used the antibiotics both as prophylaxis for infants in high risk of developing NEC, and treatment in the intervention group. 200 infants were included from 2015-2018, where the intervention group (104 infants) were treated with a combination of oral gentamicin sulfate $15 \mathrm{mg} / \mathrm{kg} / \mathrm{day}$ ev. 12 hours + nystatin $10000 \mathrm{lU} / \mathrm{kg} / \mathrm{day}$ ev. 6 
hours and a symbiotic (Lactobacillus rhamnosus). The control group received the standard treatment of empirical antibiotics (not specified). The overall mortality was $38 / 96$ in the control group compared to $13 / 104$ in the study group. For stage III infants the numbers were $28 / 35$ and $2 / 5$, respectively. The difference was statistically significant. During the investigation period no infants underwent surgery in either group. It is unknown whether they received drainage. The two older studies by Hansen et al.[18] and Vermeylen et al.[20] abandoned this practice of oral antibiotics treatment due to insufficient results. A Cochrane review[9] from 2001 supports the finding that enteral antibiotics could have a prophylactic effect on the development of NEC, but raises concerns about unknown harms. In 2014 another Cochrane review[24] concluded that the use of probiotics has an effect in preventing NEC in preterm infants. The effects found by Harutynyan et al.[23] could therefor possible be ascribed to both the antibiotic regimen and the probiotics.

Although antibiotics is a core element in the treatment of NEC some studies seem to indicate antibiotics as a risk factor[25] for developing NEC. Ampicillin and gentamicin work synergistically and have created the base for many treatment regimens for NEC[5]. Aminoglycosides are known for their side effects targeting the VIII cranial nerve and the kidneys. Hansen et al.[18] showed that the intervention group receiving oral gentamicin had significantly higher serum-gentamicin peak values compared to the control group (receiving only IV gentamicin). Although the through-levels showed no significant difference the peak values reached levels high enough to be ototoxic, questioning the safety.

One study investigating clindamycin was terminated prior to completion due to an increase in frequency of intestinal stenosis [19]. A study by Autmizguine et al.[27] analyzing data from 2780 infants with NEC who were treated with or without anaerobic antibiotic (such as clindamycin or metronidazole) showed that infants treated with anaerobic antimicrobials developed more strictures (OR 1.73; $95 \% \mathrm{Cl}, 1.11-2,72)$. However, this was not significant when looking at clindamycin alone. The study found overall lower mortality in the children treated with anaerobic antibiotics. In a study[28] with 4089 infants, no trend towards stricture formation was found. None of the studies $[19,21,27]$ showed any effect of anaerobe antibiotics on preventing aggravation on stage II infants.

Piperacillin/tazobactam might be an alternative treatment of NEC. In a small study[29] with 27 very low birth weight infants there was no strong trend towards effect/aggravation of NEC with the use of Piperacillin/tazobactam as well as no adverse events.

The limitations of this review are that many of the included studies are of older date when methodology and reporting was of a different less strict and structured format. As a result, it was difficult to obtain equivalent information from all the included studies. The heterogeneity of the included studies prevented the use of a GRADE evaluation as planned.

With the rising concerns about antibiotic resistance, efforts to find a treatment regimen with maximal effect is warranted, as is more knowledge on antibiotic treatment in the prevention and progression of NEC in addition to postoperative treatment. Another problem is the dose needed for a sufficient penetration of the antibiotic to the peritoneal cavity. The approved method with intraperitoneal microdialysis to measure antibiotic concentrations could be an option[30].

\section{Conclusion}

For now, there is not sufficient evidence to make a general recommendation on which antibiotic regimen is the most effective for infants with NEC stage II and III.

\section{Abbreviations}

NEC: Necrotizing enterocolitis. BW: birth weight. GA: gestational age. IM: intramuscular. IV: intravenous. PS: propensity score. RCT: Randomized controlled trial. N-RCT: non-randomized controlled trial. Gl: gastrointestinal.

\section{Declarations}

\section{AVAILABILITY OF DATA AND MATERIALS}

The search string for this study can be found at https://www.crd.york.ac.uk/prospero/display_record.php?RecordID=162193. For data on analysis of risk of bias in the included studies, this can be available by request to the author. 
An approval from the Committees on Health Research Ethics was not needed for this review. This review is based on published material where consent to participate was obtained in the individual studies.

\section{CONSENT FOR PUBLICATION}

Not applicable

\section{COMPETING INTEREST}

The authors of this review have no competing interests.

\section{FUNDING}

The first author of the review received funding from OUH pregraduate scholarship grant. This funding is an institutional and noncommercial. The grant offers was not involved in the work of this study.

\section{AUTHOR CONTRIBUTION}

EMG prepared the search, selection and drafted the manuscript. KJ aided in selection and analysis of included studies. NQ and MBE aided in the structure of the search and writing of the manuscript. All authors read and approved the final manuscript.

\section{ACKNOWLEDGEMENTS}

SDU Library and the Center for Evidence-Based Medicine Odense (CEBMO)

\section{References}

1. Ahle M, Drott P, Andersson R. Epidemiology and trends of necrotizing enterocolitis in Sweden: 1987-2009. Pediatrics. 2013;132:e443-51. https://doi.org/10.1542/peds.2012-3847.

2. Battersby C, Santhalingam T, Costeloe K, Modi N. Incidence of neonatal necrotising enterocolitis in high-income countries: a systematic review. Arch Dis Child Fetal Neonatal Ed. 2018;103:F182-9. https://doi.org/10.1136/archdischild-2017-313880.

3. Hein-Nielsen A, Petersen S, Greisen G. Unchanged incidence of necrotising enterocolitis in a tertiary neonatal department. Dan Med J. 2015;62:A5091.

4. Bell MJ, Ternberg JL, Feigin RD, Keating JP, Marshall R, Barton L, et al. Neonatal necrotizing enterocolitis. Therapeutic decisions based upon clinical staging. Ann Surg. 1978;187:1-7. https://doi.org/10.1097/00000658-197801000-00001.

5. Tickell D, Duke T. Evidence behind the WHO guidelines: Hospital Care for Children: For Young Infants with Suspected Necrotizing Enterocolitis (NEC), What is the Effectiveness of Different Parenteral Antibiotic Regimens in Preventing Progression and Sequelae? J Trop Pediatr. 2010;56:373-8. https://doi.org/10.1093/tropej/fmq110.

6. Jardine LA, Cartwright D, Inglis GT, Davies MW. Antimicrobial Susceptibility of Bacteria Isolated from Newborns with Suspected or Confirmed Necrotising Enterocolitis. Maced J Med Sci. 2009;2:301-4. https://doi.org/10.3889/MJMS.1857-5773.2009.0071.

7. Shah D, Sinn JKH. Antibiotic regimens for the empirical treatment of newborn infants with necrotising enterocolitis. Cochrane Database Syst Rev 2012:CD007448. https://doi.org/10.1002/14651858.CD007448.pub2.

8. Greenwood C, Morrow A, Lagomarcino A, Altaye M, Taft D, Z Y, et al. Early empiric antibiotic use in preterm infants is associated with lower bacterial diversity and higher relative abundance of enterobacter. J Pediatr. 2014;165:23-9. https://doi.org/10.1016/j.jpeds.2014.01.010.

9. Bury R, Tudehope D. Enteral antibiotics for preventing necrotizing enterocolitis in low birthweight or preterm infants. Cochrane Database Syst Rev. 2001. https://doi.org/10.1002/14651858.CD000405.

10. Scheifele D, Ginter G, Olsen E. Comparison of two antibiotic regimens for neonatal necrotizing enterocolitis. J Antimicrob Chemother. 1987;20:421-9. https://doi.org/10.1093/jac/20.3.421.

11. Sharma R, Hudak M. A Clinical Perspective of Necrotizing Enterocolitis: Past, Present, and Future. Clin Perinatol. 2013;40:27-51. https://doi.org/10.1016/j.clp.2012.12.012.

12. Knell J, Han S, Jaksic T, Modi B. Current Status of Necrotizing Enterocolitis. Curr Probl Surg. 2019;56:11-38. https://doi.org/10.1067/j.cpsurg.2018.11.005. 
13. Moher D, Liberati A, Tetzlaff J, Altman D, Group TP. Preferred Reporting Items for Systematic Reviews and Meta-Analyses: The PRISMA Statement. PLOS Med. 2009;6:e1000097. https://doi.org/10.1371/journal.pmed.1000097.

14. Covidence systematic review software. Melbourne, Australia: n.d.

15. Li T, Higgins J, Deeks J. Chapter 5: Collecting data. Cochrane Handb. Syst. Rev. Interv. 6.0 (updated July 2019), Cochrane; 2019.

16. Sterne JAC, Savović J, Page MJ, Elbers RG, Blencowe NS, Boutron I, et al. RoB 2: a revised tool for assessing risk of bias in randomised trials. BMJ. 2019;366:I4898. https://doi.org/10.1136/bmj.I4898.

17. Sterne J, Hernán M, Reeves B, Savović J, Berkman N, Viswanathan M, et al. ROBINS-I: a tool for assessing risk of bias in nonrandomised studies of interventions. BMJ 2016;355. https://doi.org/10.1136/bmj.i4919.

18. Hansen T, Ritter D, Speer M, Kenny J, Rudolph A. A randomized, controlled study of oral gentamicin in the treatment of neonatal necrotizing enterocolitis. J Pediatr 1980;97. https://doi.org/10.1016/s0022-3476(80)80283-6.

19. Faix R, Polley T, Grasela T. A randomized, controlled trial of parenteral clindamycin in neonatal necrotizing enterocolitis. J Pediatr. 1988;112:271-7. https://doi.org/10.1016/S0022-3476(88)80069-6.

20. Vermeylen D, De Laet M, Pardou A, Govaerts M, Bouton J. Neonatal necrotizing enterocolitis: from reduction of mortality to reduction of morbidity. Acta Anaesthesiol Belg. 1985;36:153-9.

21. Luo L-J, Li X, Yang K-D, Lu J-Y, Li L-Q. Broad-spectrum antibiotic plus metronidazole may not prevent the deterioration of necrotizing enterocolitis from stage II to III in full-term and near-term infants a propensity score-matched cohort study. Med U S 2015;94. https://doi.org/10.1097/MD.0000000000001862.

22. McGuinness LA. robvis: An R package and web application for visualising risk-of-bias assessments 2019. https://github.com/mcguinlu/robvis.

23. Harutyunyan A, Muradyan A, Hovhannisyan M, Badalyan A, Lorenc D, K.v N, et al. The transformation of multi-modal 3 component preventive scheme into treatment protocol for necrotizing enterocolitis in newborns. New Armen Med J. 2019;13:89-102.

24. AlFaleh K, Anabrees J. Probiotics for prevention of necrotizing enterocolitis in preterm infants. Cochrane Database Syst Rev. 2014. https://doi.org/10.1002/14651858.CD005496.pub4.

25. Raba AA, O'Sullivan A, Semberova J, Martin A, Miletin J. Are antibiotics a risk factor for the development of necrotizing enterocolitis-case-control retrospective study. J Pediatr. 2019;178:923-8.

26. Murphy C, Nair J, Wrotniak B, Polischuk E, Islam S. Antibiotic Treatments and Patient Outcomes in Necrotizing Enterocolitis. Am J Perinatol. 2020;37:1250-7. https://doi.org/10.1055/s-0039-1693429.

27. Autmizguine J, Hornik C, Benjamin D, Laughon M, Clark R, Cotton C, et al. Anaerobic antimicrobial therapy after necrotizing enterocolitis in VLBW infants. Pediatrics. 2015;135:e117-25. https://doi.org/10.1542/peds.2014-2141.

28. Greenberg R, Wu H, Maharaj A, Cohen-Wolkowiez M, Tomashek K m, Osborn B I, et al. A Pharmacoepidemiologic Study of the Safety and Effectiveness of Clindamycin in Infants. Pediatr Infect Dis J 2019.

29. Berger A, Kretzer V, Apfalter P, Rohrmeister K, Zaknun D, Pollak A. Safety evaluation of piperacillin/tazobactam in very low birth weight infants. J Chemother. 2004;16:166-71. https://doi.org/10.1179/joc.2004.16.2.166.

30. Marchand S, Chauzy A, Dahyot-Fizelier C, Couet W. Microdialysis as a way to measure antibiotics concentration in tissues. Pharmacol Res. 2016;111:201-7. https://doi.org/10.1016/j.phrs.2016.06.001.

\section{Figures}




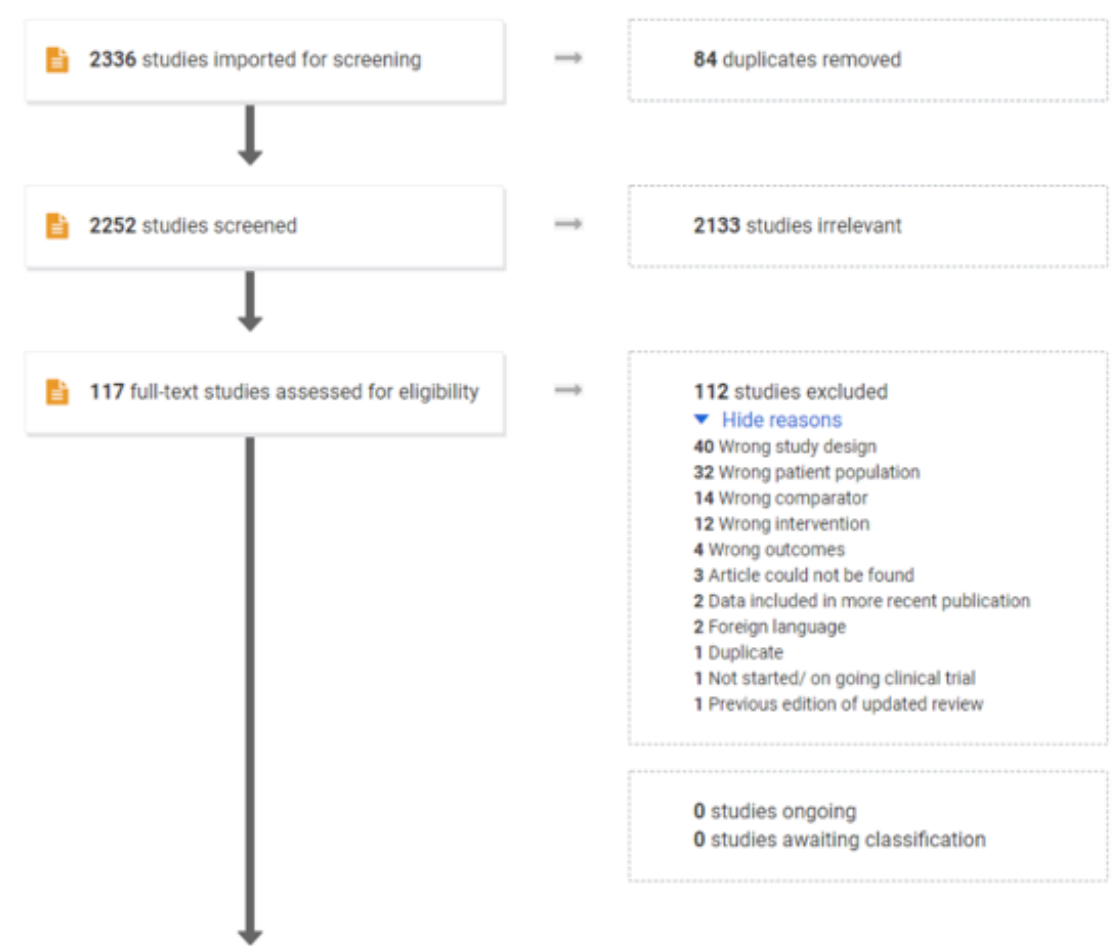

E $\mathbf{5}$ studies included

\section{Figure 1}

Original search flow from PRISMA.

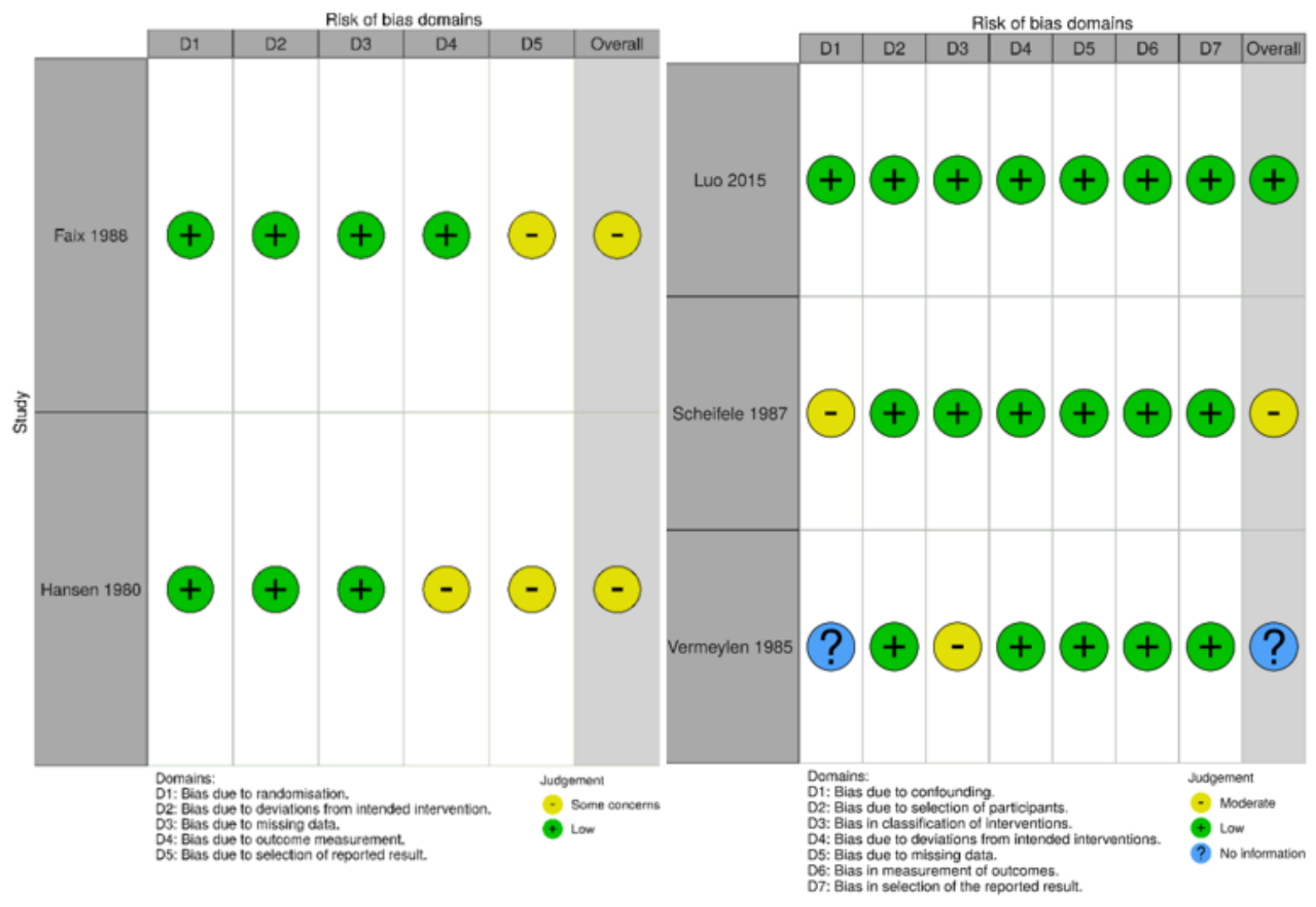




\section{Figure 2}

Traffic light plots for individual risk of bias in the included studies. Left: RCT, Right: n-RCT. Both plots were created using Robvis23. Green indicates low risk of bias, yellow some concern and blue no information.

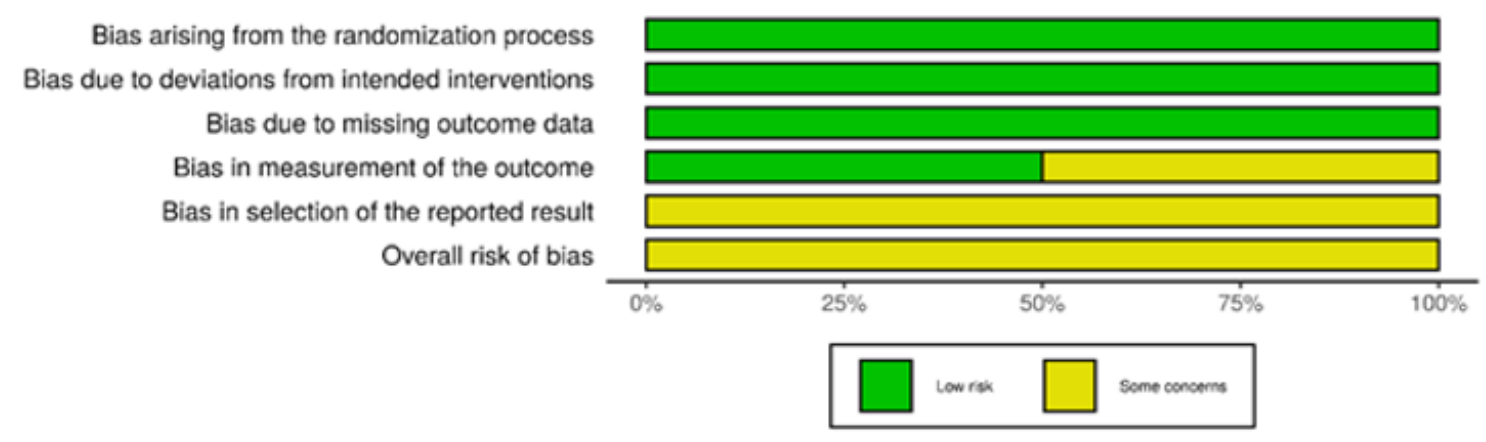

Bias due to confounding Bias due to selection of participants Bias in classification of interventions Bias due to deviations from intended interventions

Bias due to missing data Bias in measurement of outcomes Bias in selection of the reported result Overall risk of bias

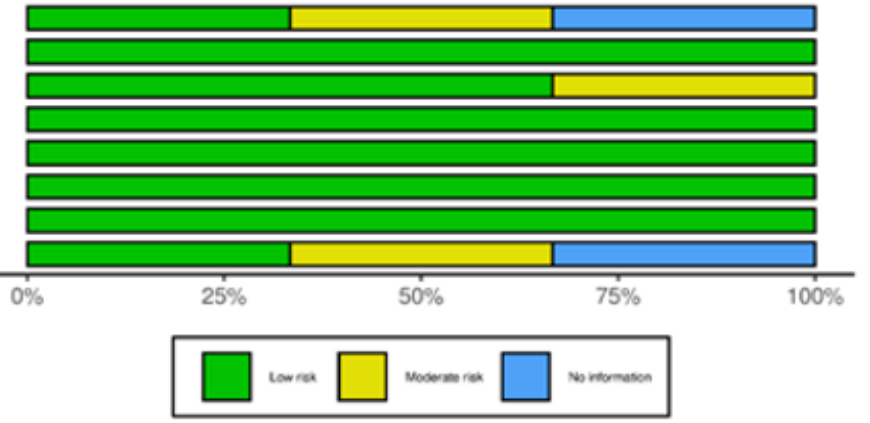

\section{Figure 3}

Summarized bias across studies. Top panel for RCT, lower panel for n-RCT. The plots were created using Robvis 23

\section{Supplementary Files}

This is a list of supplementary files associated with this preprint. Click to download.

- PRISMAchecklist.docx 